\section{Secrecy in the NHS}

\section{NHS chief executive wants a culture of openness}

EDITOR,-The "evidence" of Stalinism in the running of the NHS presented by Naomi Craft and colleagues does not warrant the exaggerated claims made for it.' A manager "advised" not to publish articles critical of current policy nevertheless does so; is this Stalinism in action? Bugging of a telephone-a deplorable action-is cited, but the fact that the chief executive concerned promptly departed from her post is omitted. This collection of anecdotes does not bear objective scrutiny and has no place in a reputable journal that sets the highest standards of evidence in its coverage of clinical and scientific matters.

I am appalled at the thought that there remain in the NHS some people who feel that they work in a climate that prevents them from freely expressing their views. That is not the kind of organisation I wish to lead. I do not believe that there is any place for "confidentiality for commercial reasons" in the family of the NHS.

I want the network of public health specialists to grow in strength by increasing its direct influence over the development of policy. I want people to make a reality of our commitment to make more information available to the public through the patient's charter and the code of opennesssubject only to our commitment to patient confidentiality. I want no barrier to the free flow of information supporting the development of medical science.

Doctors and managers in the NHS have a collective and an individual responsibility to help maintain a culture of openness within the service. Making sure that this happens is not a job for the "thought police"; it is a question of leadership at every level of the service.

NHS Executive,

Department of Health

Leeds LS2 7UE

1 Craft N, Sheard S, Smith R. The rise of Stalinism in the NHS $B M F$ 1994;309:1640-5. (17 December.)

\section{Wide public consultation in Cambridge and Huntingdon}

EdrTor,-Naomi Craft and colleagues raise several questions that need to be addressed by the NHS Executive-sooner rather than later. ${ }^{1} \mathrm{We}$ were shocked and surprised at the cases highlighted as they seem to be at variance with our experience in Cambridge. Cambridge and Huntingdon Health Commission prides itself in retaining a culture in which people can challenge from within. Often the most creative people are difficult to live with; they present many challenges, but ideas that are seemingly subversive and controversial can become the informed and innovative policy of tomorrow.

We try to involve both the public and staff in our decision making and have a range of methods of doing this. We invest heavily in finding out public opinion because we believe that our public has a worthwhile contribution to make to our planning process. We have six board meetings a year, at which all important decisions are made; the public

\section{Advice to author:}

We prefer short letters that relate to a recently published article and we are unlikely to publish letters longer than 400 words and containing over five references. Letters may be shortened. Your letters should be typed with double spacing and include a word count. All authors need to sign the letter and provide one current appointment and address. We encourage you to declare any conflict of interest. Please enclose a stamped addressed envelope if you require an acknowledgment.

is welcome to attend. We also consult extensively with users and the informed lay public. Recently we took our draft purchasing plan to several groups in outlying small towns and high density residential areas so that we could have a different perspective on it. Our focus groups include people from a wide variety of backgrounds, and we have found their insight to be of particular benefit when we finalise our strategies. All those involved during the consultation period are notified of how their comments have influenced our final stretegy.

Rather than gag our staff we encourage them to talk direct to the media. We promote this by providing special training to give them confidence in oral interviews and and in dealing with the media.

We believe that we are pursuing an open and honest management style in which staff and the public are encouraged to make their views and opinions known. Clearly, other parts of the NHS need to follow our lead.

MARGARET SCOT Chairman STEPHEN THORNTON

Cambridge and Huntingdon Health Commission Chief executive

Fulbourn Hospital,

Cambridge CB1 5EF

1 Craft N, Sheard S, Smith R. The rise of Stalinism in the NHS $B M f$ 1994;309:1640-5. (17 December.)

\section{Threat of action for libel}

EDITOR,-The $B M F$ is to be congratulated for its strong stand against the insidious erosion of freedom of speech in the NHS. ${ }^{1}$ As Smith notes, one of the mechanisms by which this is being executed is the threat of action for libel, something of which I have personal experience. A recent ruling by the law lords may give some support for those who seek to foster a free and open debate about the NHS reforms. ${ }^{2}$

The judgment dealt with a local authority rather than a trust or a health authority. Nonetheless, a key part of the judgment was that "not only is there no public interest favouring the right of organs of government whether central or local, to sue for libel, but that it is contrary to the public interest that they should have it... because to admit such actions would place an undesirable fetter on freedom of speech." A crucial issue is the extent to which a trust or a health authority can be judged to be an organ of government, given the dubious lega basis under which trusts have been established.
The judgment, however, drew on a previous one, which had stated that those "responsible for public administration must always be open to criticism." While the law as it relates to the specific situation of trusts may need to be tested, the principles seem clear.

Department of Public Health and Policy, Health Services Research Unit, London School of Hygiene and Tropical Medicine, London WC1E 7HT

1 Craft N, Sheard S, Smith R. The rise of Stalinism in the NHS $B M F$ 1994;309:1640-5. (17 December)

2 Derbyshire County Council $v$ Times Newspapers Ltd and others. [1993] 2 WLR 449.

3 Hector $v$ attorney general of Antigua and Barbuda [1990] 2 AC 312.

\section{Dismissal means denial of right to practice}

EDITOR,-The two particular concerns expressed in the articles on secrecy in the NHS-namely, the status of public health doctors and freedom to talk to the press-are examples of bluff by the management. ${ }^{1}$ The British government told the European Court of Human Rights that doctors were not civil servants and so could not be ordered about like civil servants (this was conceded in the case of Damell $v$ the United Kingdom ${ }^{2}$ ). This principle had previously been established in the European Court of Human Rights in other cases involving the special characteristics of a profession.

The NHS is a monopoly employer of hospital and public health doctors. Dismissal therefore means being denied the right to practise as a doctor. In all states in the European Union, to practise as a doctor is a civil right granted by those bodies empowered by law to issue the appropriate licences-for example, the General Medical Council. Civil rights can be removed only after a fair trial by a body appointed by law, according to article 6 of the European Convention on Human rights. ${ }^{3}$ Unlike civil servants, public health doctors therefore have the legal right as well as a moral, ethical, and professional right, without threat of dismissal, to speak out on any public health matter-for example, on any action by a hospital trust that endangers the public health, be it its disposal of clinical waste or cutting of a vital clinical service.

Under article 10 of the European Convention on Human Rights everyone has the freedom of speech and expression subject to such obligations as the security of the state and the freedom and wellbeing of other individuals. ${ }^{3}$ This human right cannot be taken away by any employer, nor can it be a condition of employment: except where immediate threat to national security is concerned, no state or state run monopoly nor any of its branches or "trusts" can make the suspension of a human right a condition of employment. The English courts have also determined that it is legal to criticise a public body such as a health authority without fear to criticise a public body such as a health authority without fear of libel or any threat flowing from an allegation of bringing the service (or hospital trust) into disrepute. It therefore follows that anyone threatened with suspension and dismissal should take out a legal injunction to remove the threat of dismissal as being contrary to European law.

There have been a number of attempts to discipline and dismiss doctors (including one 